\title{
A Proposed Approach of Case-based Design in Teaching Architecture in Jordan to Support Building Information Modeling
}

\author{
Wael W. Al-Azhari \\ Department of Architecture Engineering, School of Engineering, the University of Jordan.
}

ORCID: 0000-0001-8158-5570 (Wael Al Azhari)

\begin{abstract}
Case-based Design (CBD) is a cognitive method in design, which depends on other experiments to solve problems and reach a solution. It is an important technology in starting an architectural design project. It can be very useful in architectural design education, especially for novices' students who lack designing knowledge. The students' main recourse is the experience of others who involve previously in related architectural design problems. Therefore, a design case-study gives architecture students an information that are needed for solving design problems. In the contrary, Building Information Modeling (BIM) gives a systematic methodology in architectural projects that all project aspects are considered during the design phase. BIM is a method to understand the project, which gives an informational framework, which relates project information in a systematic way. BIM is usually introduced, only, into architectural students through a Computer-aided Design (CAD). Novices architecture students lack of experience and knowledge to analyze and organize different aspects of designing a project. The paper proposes a design framework in architectural BIM education in which students can generate a Knowledge-based Modeling (KBM) depending on CBD. A basic set of design rules and guidelines with CBD ideas are proposed to be taught to the students in a sequential manner. The findings show that in order for these rules to be useful in architectural education, there should be a set of cases that are related to the different aspects of the design project. Design works of students are presented and analyzed to check the proposed CBD approach that works in architectural teaching. The paper concludes in suggesting a BIM comprehensive matrix that includes CBD aspects as teaching competences in architectural education in Jordan.
\end{abstract}

Keywords: Building Information Modeling (BIM), Casebased Design (CBD), Design Problem, Architecture Design, Architecture Education.

\section{INTRODUCTION}

Architectural design approach is different from other disciplines, because it is dealing with uncertain aspects in environment. It is an activity, which deals with external imposed problems, the analytical rational, and internally drawn inspiration, the creative (Kalay, 2004).

Design problem are ill-structured according to Simon (1992), and wicked according to Rittel and Webber (1973); they do not have enough information to be solved, and uncertainties to deal with. Design is a process generate and organize ideas to new situations to deal with ill-structured problems to change to a well-structured one. Design problems are formulated by satisfied predicates. The designer's task is to find a strategy of the design world satisfying the predicates (Mitchell, 1990). These predicates defined by Kalay (2004) as habitual methods that depend on analogical similarities in synthesis which are precedents or cases; if the solution has proved to be successful in the past it should be so again in the future. This method cannot guarantee that there will be a solution to the problem or if this solution are optimal. It is ruled-based method; depend on observations, knowledge, and experience in dealing with such problem.

Case-based Design (CBD) is a design process in architecture depends on a knowledge-based analysis of recognition. CBD argues that the experience comes from knowledge, which organized as precedents, design cases, in human mind and not only as rigid rules. It depends on remembering to relate and compare from the past a situation or more to a situation in present (Martin, Heylighen, and Cavallin, 2005).

Rahman, Ayer, and London (2019); Reizgevicius, et al. (2018) had identified several of the most critical skills for individuals to have to address common process related to Building Information Modeling (BIM) problems. These identified skills include analytical and problem solving, communication, and planning. These skills are necessary for BIM modules (Wu and Issa, 2014). In other BIM fields, researchers have established the potential of design problems for increasing these skills, especially for students (Agirbas, 2020); (Boton, Forgues, and Halin, 2018). Some educational researchers in the BIM domain have also published works that illustrate the potential for learning depending on problems to support BIM education (Kocaturk and Kiviniemi, 2013); (Lee, Lee, and Ahn, 2019). While there is evidence that problem-based learning can support BIM education and the skills necessary for resolving critical BIM issues, a systematic process for developing useful BIM that are related to problemunderstanding does not currently exist (Rahman, Ayer, and London, 2019). This lack of a structured methodology can lead to potentially ineffective educational strategies that fail to realize the theoretical benefits suggested by prior literature (Vinsova, et al., 2015).

This paper is providing a structured process for developing a Building Information Modeling (BIM) approach that can be used in architectural educational systems depending on Casebased Design (CBD) concept, and for defining an implementation process for the approach (Motawa and 
Almarshad, 2015). The approach aligned with the design problems and technological needs that students experiment in design projects. As the problems observed on design projects, this approach will enable educational researchers to update learning systems to create learning experiences and knowledge that successfully for teaching architectural students, as well as, in career practice.

\section{CASE-BASED DESIGN (CBD)}

Case-based Design (CBD) gave first, ideas into what is architectural design means from designer own experience, and the second, understands the design by the experience of others.

\subsection{CBD Framework}

Suwa and Tversky (1997) argued that cases are segments, and they define a fragment to have a conceptual dependency to a past fragment, that could have the same item/space/topic. They found that there are many adjacent segments blocks, and they call each block a dependency chunk, and they call segments, which standalone isolated segments, Figure 1. These fragments are indexed and organized according to four modes of cognitive actions, which are: physical, perceptual, functional, and conceptual, which Ericsson and Simon (1993) called it protocol analysis.

\begin{tabular}{|c|c|c|}
\hline Major category & Subclasses & Examples of phrases in protocols as evidence \\
\hline \multirow[t]{4}{*}{ Emergent properties } & Spaces & "Areas", "places" \\
\hline & Things & Descriptions or names of somcthing \\
\hline & Shapes/angles & $\begin{array}{l}\text { "Round", "prolonged", "wavy line", "too sharp } \\
\text { a comer" }\end{array}$ \\
\hline & Sizes & "Big", "tiny", "narтuw" \\
\hline \multirow[t]{2}{*}{ Spatial relations } & Local relation & "Adjacent", "far", "connected", "lined up" \\
\hline & Global relation & "Symmetrical", "configuration", "axis" \\
\hline \multirow[t]{5}{*}{ Functional relations } & Practical roles & "A ticket office should be close to an entrancc.." \\
\hline & Abstract features/reactions & $\begin{array}{l}\text { "Waves/forces (from this shape)", "good show } \\
\text { to visitors" }\end{array}$ \\
\hline & Views & "View line", "the appcarancc (of this building)" \\
\hline & Lights & "(This place is always) bright, having sunshine" \\
\hline & Circulation of people/cars & "People meander through (this narrow space)" \\
\hline \multirow[t]{2}{*}{ Background knowledge } & - & "Postbeam structures", \\
\hline & & "An important thing in an urban setting is..." \\
\hline
\end{tabular}

Figure 1. Information Categories and their Subclasses. Source: (Suwa and Tversky, 1997).

Akin (2002) suggested different strategies to match a case to a problem, which are:

- Solution matching; it uses small adjustment for the current problem.

- Sub-solution matching; it synthesizes into a solution for the current problem.

- Space matching; the set of precedents is used to limit the investigation of the current problem.

- Process matching; it uses the precedent's approach or process.

Therefore, a well-documented case, stored within a case tool, can support useful design tasks, like generating, evaluating...etc.

\subsection{CBD in Architectural Practice}

Many design problems in CBD meet similar goals; and the solutions that meet them are similar too. The core of CBD is a group of detailed cases stored as separate sets of patterns of experience and labeled by important issues (Richter and Aamodt, 2005). CBD starts with an old solution to a similar problem and adapt it to the new needs, which is a prototype.

CBD is a defined process that used to reproduction new results for architectural design problems. An architectural case is the codification of all of the information needed to describe a CBD (Akin, 2002).

According to Kalay (2004), prototypes are common method to capture and apply architectural similarity. They are grouping of elements in particular design domain, including sets of elements (syntax), their information (semantics), their relationships, and parameterized (numerical) descriptions. To use a prototype, the designer must first identify the proper 
characteristics of the problem to match the prototype. To use the prototype in design is predicated. The cases form a basis for hypotheses. The hypotheses verifying by the development of a prototype and testing this prototype in an experimental setting developed design interface (Segers, 2004).

March (1976) argued that a case could controlled by a rule. After that, the case will evolve to a solution, which March name it as a result. This could be summarize as:

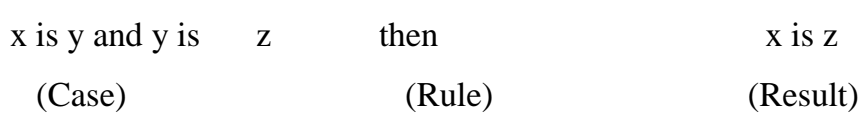

Therefore, human recognition is a process of identification prior situations and link it to present ones. CBD uses indexing to locate the right solution to the problem in hand, which depends on labelling codes with one or more set of indicators compared with the design constraints.

The guidelines, which could relate indices relevant to the design aspect, according to Heylighen (2003) are:

- Actors are individuals or groups who make decisions about a project.

- Context is the physical location of the project.

- Organization is the rules' set of structure.

- Practices are the methodologies and the tools used.

- Program is the user/client needs and requirements.

Architects suggest, during their design, a source of architectural cases, because to predict is to get the result. Students, in contrast, lack of this source of knowledge. Therefore, tutors connect students into real design projects and introduce them to applicable architectural problems (Heylighen and Verstijnen, 2003).

\subsection{CBD in Architectural Education}

Design education depends on learning in action. It requires a form of knowledge. Knowledge that depends on experience is considered the basis of CBD. CBD claims that knowledge in human cognition are cases-based depends on actual models (Martin, Heylighen, and Cavallin, 2005). Therefore, cases are very powerful tool for students' creativity, when they direct it directly onto the main design problem and the evidences of the danger of design fixation when using cases are less. However, some architectural tutors believe that exposure to too many cases, for students, increases the danger of design fixation, which blindly coping existing projects (Martin, Heylighen, and Cavallin, 2005).

Creativity is the adaptation of old stories (cases) to new purposes, purposes to which they have never been applied before, so it is to discover a partial match. In that aspect, Schank (2000) argues that cases are richer than rules, richly indexing, and easier to pattern and rethink.

The principles within the design are different from other educational fields is that these principles are focused on the out-coming solutions rather than principles or theories. Therefore, teaching guidelines will be different. Learning through CBD could take place through examination, analysis, and abstraction of the information from cases (Motawa and
Almarshad, 2015).

This abstraction is important in bridging between the conceptual and the physical variables, which are the core of spatial design (Akin, 2002). When students analyzed the cases, they understand them as physical components, and then they starting abstracting design conceptual aspects.

\subsection{CBD in Computer Cognition}

CBD was developed to be easily understood and to mimic computer cognition. It starts form human way of thinking in which knowledge experience are closely interrelated to learning.

The relationship between knowledge and experience in design has stimulated CBD researchers, Akin (2002), to develop different of CBD tools in order to help designers and architects in increase design experience that is needed in design. Some examples of these tools are:

- SEED is a tool that supports the first stages of design process. It was a case-based system deriving its knowledge from stored prototypes. Case-based Design (protocols); in which the design solutions are adapted and evolved from earlier solutions to similar design problem (Flemming, et al., 1997). CADRE is a tool the same as SEED for building design (Hua, Faltings, and Smith, 1996).

- FABEL is a tool for generating technical details of buildings (Schmidt-Belz, and Hovestadt, 1996).

- Archie is a tool that give prototypes for designing courthouse (Domeshek, and Kolodner, 1993).

- IDIOM is a tool that gives different apartments' layouts (Smith, et al., 1996).

- PRECEDENTS is a tool that help in designing museums (Oxman and Oxman, 1994).

- EDAT is a tool that assists training to use case-based design and it is a centralized store for research documentation gathered by students in the early stages of design. It has a greater depth of information, as precedents that could be taught at architectural design studio (Akin, 2002).

- DYNAMO (Dynamic Architectural Memory On-Line) (Martin, Heylighen, and Cavallin, 2005). It is almost the newest tool, which is until now it is supported design cases under an internet site; https://dynamobim.org/. It is considered an inter-active workhouse, in which students can navigate between the cases change and improve cases in memory. It is a platform offers students and architects a source of inspiration, ideas, and design knowledge, through collection of design cases focusing on expeirnce as a learning process. It is an actual memory content; a database that structures this content and a user interface to modify it (Heylighen, 2003). Students can download free DYNAMO SANDBOX platform, Figure 2, which is an open source environment for visual programming. The importance of the platform is to enable students and 
International Journal of Engineering Research and Technology. ISSN 0974-3154, Volume 13, Number 10 (2020), pp. 2637-2646

(C) International Research Publication House. https://dx.doi.org/10.37624/IJERT/13.10.2020.2637-2646

teachers to share material and ideas about design projects

and to learn from each others' analysis.

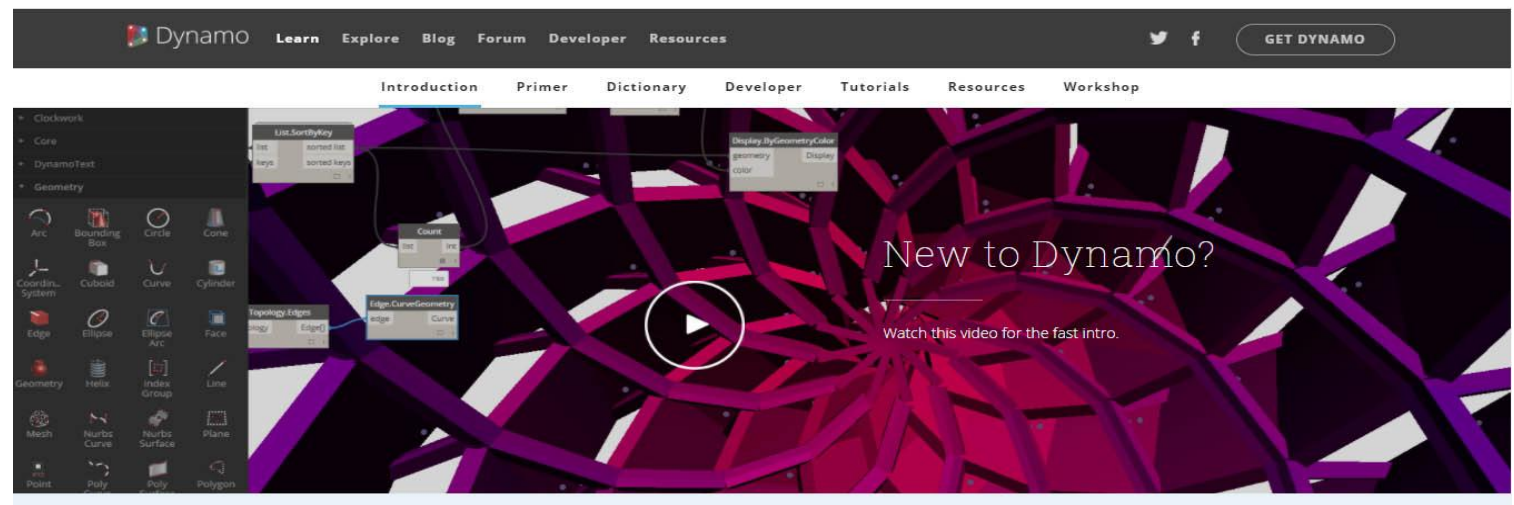

Figure 2. DYNAMO Platform. Source: (https://dynamobim.org/, retrieved September 2020).

\section{Building Information Modeling (BIM) Theory}

Modeling information through computers to generate designs are still new compared to other industries. But it is a common metghod for product design to experiment design models, because it deals with a final product that could be evaluate. There are less to be implemented in building industry (Rahman, Ayer, and London, 2019).

\section{$\underline{3.1 \text { BIM Background }}$}

Building Information Modelling (BIM) is an idea that had been created according to Charles Eastman at the Georgia Tech School of Architecture in late 1970 (Reddy, 2012). After that, BIM implementations have been developed into different ways. Marcos (2017) suggested six notions of BIM concepts that are design, assessment, construction, building life cycle, performance, and technology (Marcos, 2017).
BIM offers the possibilities of digitally including all of these options into the same digital design model and thus the same actual design process. BIM is part of what is called digital turn, but unlike other digital tools it is oriented for engineering tasks. The necessary standards of BIM are oriented to construction industry as well as for CAD software companies.

BIM is very useful to be used in computer technology. It can cope with the construction information of a project through joining design aspects to production systems. It is a consistent process representing all design components visually (Rogers, et al., 2015.

Reizgevicius, M., et al. (2018) suggest a BIM model lifecycle that integrated all BIM phases and duties. They generate it as a cycle framework that consists nine main phases to produce a BIM modeling system that could work on engineering industry. Each phase is divided into set of producers that could be related, Figure 3.

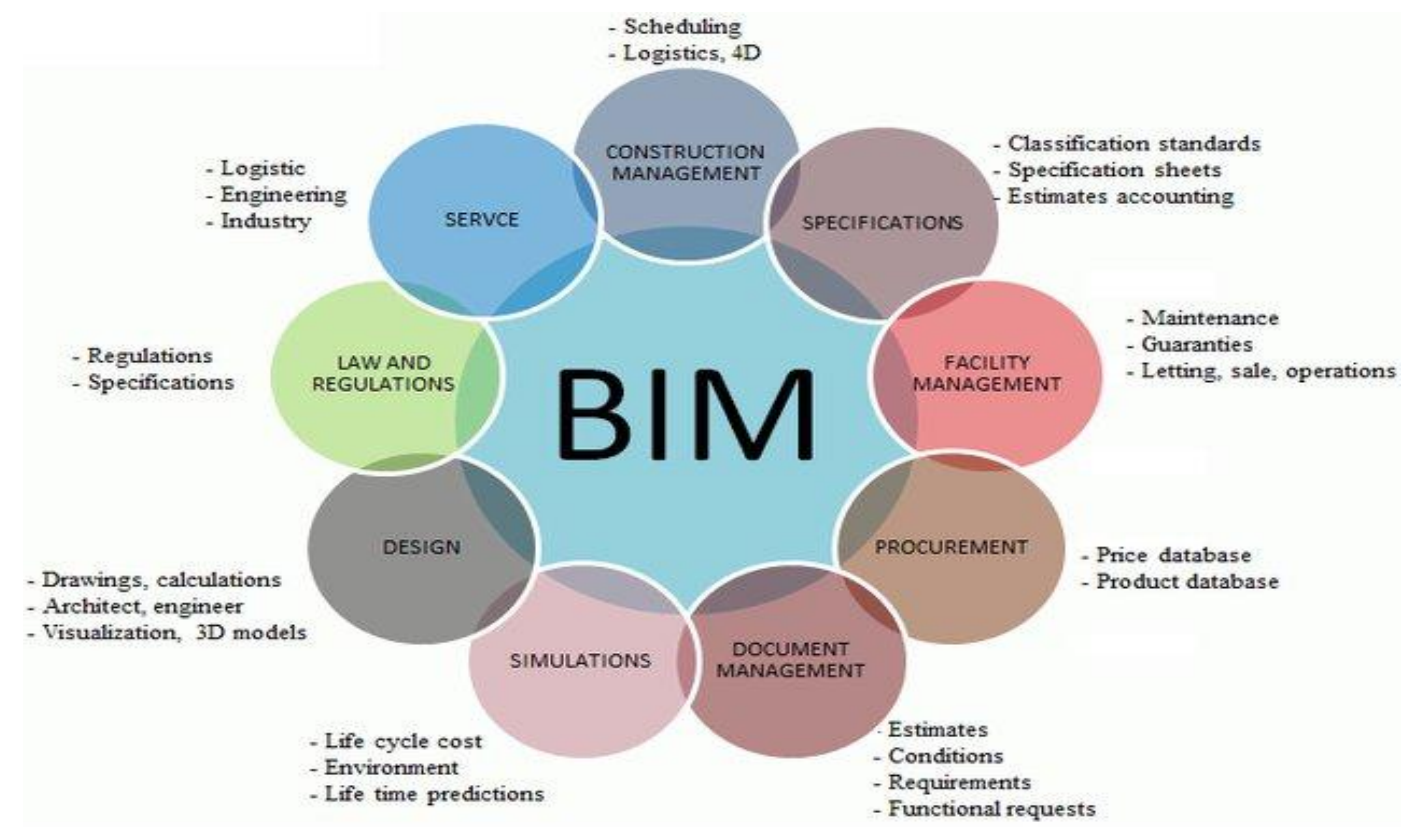

Figure 3. Building Information Modeling (BIM) Lifecycle View. Source: (Reizgevicius, et al., 2018). 
Constructing and design operation can be increased when using BIM and it gives project's stakeholders a clear vision to design and construct projects (Lee, Lee, and Ahn, 2019). Using BIM ideas are important in different stages of an engineering project. It is useful in the first stage of generating a project, which is design. In addition, it is helpful in estimating the project budget, finding technical clashes, organizing project documentations, and planning in a head (Olatunji, 2019).

Therefore, BIM ideas provide a constructive effect not only on environmental aspects of design, but also on economic and social ones. According to Reizgevicius, et al. (2018), BIM helps design in three levels, which are:

- In environment, it is because BIM has the ability to store and recall all shared information of the project, it will be possible to reduce the impact of environmental hazards, i.e. waste, water and energy consumption, carbon emissions etc.

- In economic, it is important in early detection of possible clashes. Also, it give more understating of design decisions for all project stakeholders, an exact evaluation for building costs in different design levels (Chen, et al., 2019).

- In social, it is the ultimate goal for any design is to create healthy, comfort, and livable spaces. BIM is useful in introducing this goal through i.e. indoor air quality, noise pollution, and protection. Using BIM in this way make building more sustainable and also encourages interaction among users (Rogers, et al., 2015).

\subsection{BIM Integration into Architecture Education}

Few architectural schools in Arab World have yet improved of making CAD or even BIM a mandatory part of the learning syllabus. Introduction BIM ideas in architectural education is a little bit difficult, because most of architectural programs are full of different levels of courses, starting from basic design and drawings, building material and construction, structural systems, Design history, legislations, and interior design etc. The only courses that could be introduced BIM ideas are through design studios. In addition, architectural programs competences are using CAD and BIM ideas as production tools and hardly implemented in the early stages of architectural design (Berwald, 2008).

In architectural schools, students learn through fragmentation; to divide design problems into small chunks or fragments, in which they try to connect them according certain criteria. Dealing with fragments ensure that each one of them can be solved and handle, but the whole composition will still not clear, and immature, that give the student the difficulty to finish a design (Kocaturk and Kiviniemi, 2013).

CAD/BIM can be trained in parallel to a design studio or it can be given in handle its own design studios with small design problems to handle. This will give students the ability to understand the sequential nature of design in building production, which is important to deal with ill-structured of design and the cases that could develop a design. In addition, they will learn producing precise drawings and technical details (Techel and Nassar, 2007).

This is important, as students are not only to learn how to draw lines, arcs, circles, etc., but also to understand the procedural nature of the building design process and how $\mathrm{CAD} / \mathrm{BIM}$ tools are structured to assist in the process. Students cannot fully comprehend these very specific structures for as long as they do not understand the design process itself, and the cases that could develop a design. Therefore, a CAD/BIM training cycle can be included (Olatunji, 2019):

- Technical abilities in dealing with different situations.

- Basic design information of aesthetic and functions ideas.

- Interpretation understating of their abilities to generate more compositions that are complex.

- Skills to criticize the respective design ideas.

- Skills to produce more design alternatives to be evaluated.

- Ability to communicate and to understand design setbacks.

For that, architectural schools judge and evaluate designs according to aesthetic rubrics, i.e. form, color, height, etc. Therefore, several architectural schools that have covered digital modeling generated under formal aspects, especially Autodesk software modelers, i.e. 3ds Max, Maya, or Revit. In addition, to other rendering engines, i.e. V-ray, Lumion 3D, or Corona render (Vinsova et al., 2015).

These modelers, sometimes, does not reflect the complete understanding of the design construction. Different construction elements, i.e. walls, beams, and slabs have differing material properties that need to be imitated in producing an architectural design. Their proper understanding needs to be reflected in the overall design. Students should be introduce to spatial organization rules and more understand of material behavior and properties. Generating design models could be useful to understand the aesthetics values of the design but it is hard to capture all these tests at the same time. Therefore, CBD will give students the knowledge in dealing with most of the design generators under the BIM framework.

\section{CBD IMPLANTATIONS INTO BIM}

Architects, during design, recover previous cases for considering small design features rather whole scale information, so cases used as evidence for a design which is already generated (Akin, 2002). However, to use of a case to generate complete and complex solution is depending on casebased design approaches that could be explained by BIM, 
especially in education.

\subsection{The CBD Informative Architectural Design Matrix}

Rahman, et al. (2019) suggested a module to adopt learning skills rubrics for evaluating the Specific, Measurable, Assignable, Realistic, and Time-based (S.M.A.R.T.) criteria to evaluate the module's impact on students. These criteria could organize the CBD in a way that could be workable and practical for novices' students. They are associated with what Kalay (2004) understands for a design process for teaching, which are; Assimilation, Analysis, Synthesis, Evaluation, and Communication. The association can have five phases, which are:

- Specific is associated with Assimilation; which is the ability to identify to choose effective precedents that could suggest solutions.

- Measurable is associated with Analysis; which is the ability to identify and to evaluate all the compatible sets of sub-solutions.

- Assignable is associated with Synthesis; which is ability to allocate resources to implement initiatives. It is the creative phase where the designer generates ideas and possible solutions that might achieve the goals that established during the analysis phase.

- Realistic is associated Evaluation; which is the ability to complete distortion solutions that emerged from the Synthesis phase with practical intelligence.

- Time-based is associated with Communication; which is the ability to understand managing of the evolving goals and solutions, because it is a process of encoding and decoding information to be understood.

Suwa and Tversky (1997) argued that the design is a process that focuses on design problem contents; it is a set of data categories and their subclasses. They examined the information that architects use during their designs, which is important in generating and visualizing their idea. They suggested three information categories, which are:
- Depicted elements, objects, spaces, or icons, they call them Emergent Properties.

- Spatial relations, sizes, local, and global relations.

- Abstract conceptual relations, which is the functional relations.

Related to that, Reizgevicius, et al. (2018) described BIM as a management process of information that explain the integrated data that sorted and implemented in the process and the digital data that were generated. They stated three classical dimensions to look into any design. They found that BIM generates different design alternatives dealing with constructing, preserving, and retiring buildings. Therefore, BIM implementations can have a helpful effect on environmental aspects of design and on economical and social ones, as well.

According to that an informative matrix is proposed, that give students and novices designers, especially architects, a medium to design on a sequential process. The proposed matrix is used the five phases that of CBD that Kalay (2004) suggested and the associated BIM phases that Rahman, et al. (2019) examined. These phases are linked to three architectural categories that are important to generate a design project, which are the three information categories that Suwa and Tversky (1997) set, and the three dimensions that Reizgevicius, et al. (2018) described. The three architectural categories are divided into eight design issues, which are:

- Environmental (Contextual Aspects): design norms, and site physical characteristics.

- Economic (Functional Relations): project areas, material, and technology.

- Social (Spatial Relations): history, design requirements, and social characteristics.

These aspects should be seen in the design phases in different levels, according the project type and in which stage the design is, Table 1. Three alternatives of design cases for the same design project is in Figure 4.

Table 1. The CBD Proposed Informative Architectural Design Matrix, according to the Eight Design Issues. Source: (The Author, 2020).

\begin{tabular}{|l|c|c|c|c|c|}
\hline & Assimilation & Analysis & Synthesis & Evaluation & Communication \\
\hline & Specific & Measurable & Assignable & Realistic & Time-based \\
\hline Environmental (Contextual Aspects) & 1,2 & 1,2 & 2 & 2 & 1,2 \\
\hline $\begin{array}{l}\text { Economic } \\
\text { (Functional Relations) }\end{array}$ & $3,4,5$ & 3 & 3,5 & $3,4,5$ & $3,4,5$ \\
\hline $\begin{array}{l}\text { Social } \\
\text { (Spatial Relations) }\end{array}$ & 6 & 7,8 & 7 & 7,8 & $6,7,8$ \\
\hline
\end{tabular}




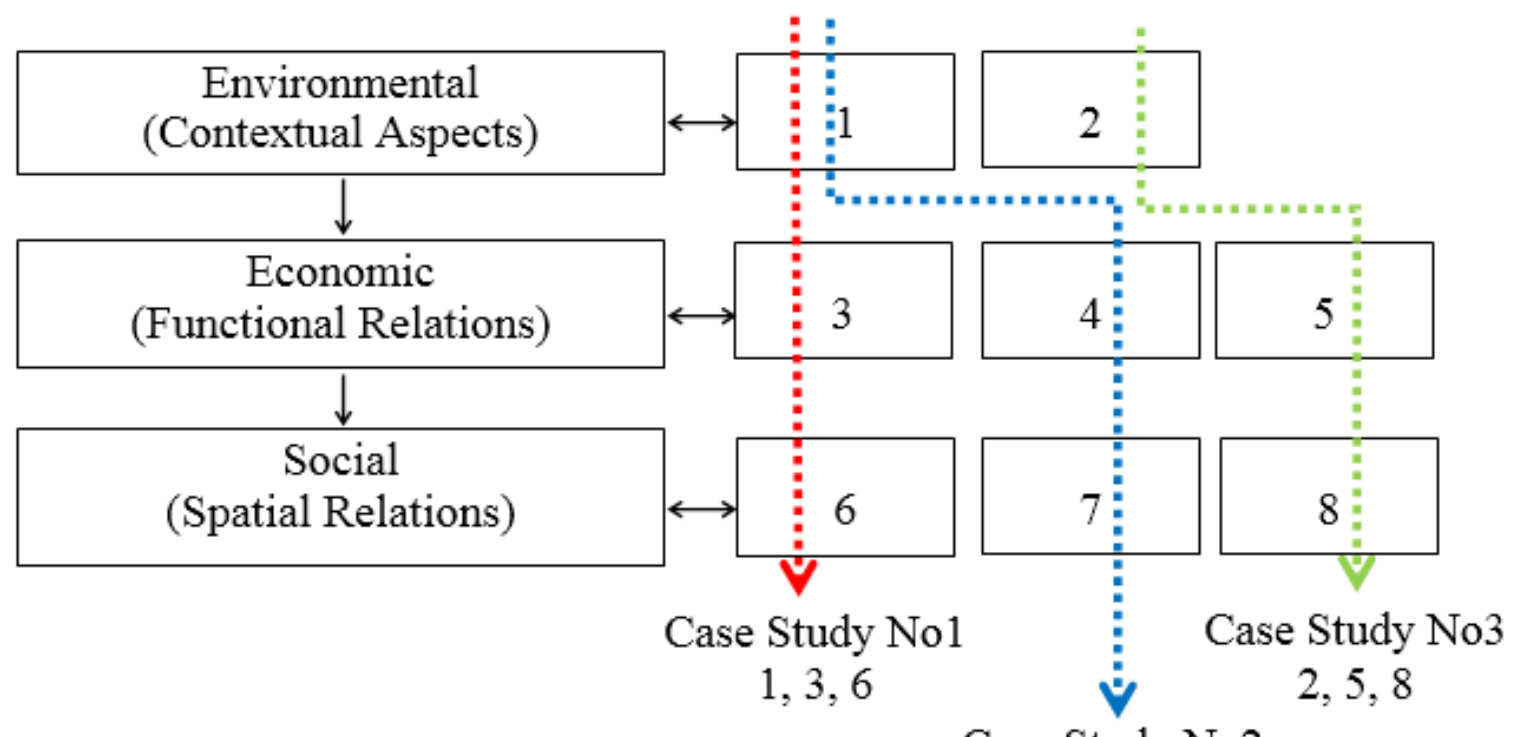

Case Study No2

1. 4.7

Key: 1. Design Norms. 2. Site Physical Characteristics. 3. Project Areas. 4. Material. 5. Technology.

6. History. 7. Design Requirements. 8. Social Characteristics.

Figure 4. Three Design Cases related to the Same Design Project after CBD Design Matrix. Source: (The Author, 2020)

\subsection{The Students Experiment}

To check the CBD matrix, an experiment involved 32 forth year students of the Faculty of Architecture and Design at Middle East University (MEU) in Jordan. The tutors divided the students into two design groups according to the two projects that have been chosen, which are: Airport Urban Renewal Project, Figure 5 and AlGiza Railway Station Project, Figure 6.

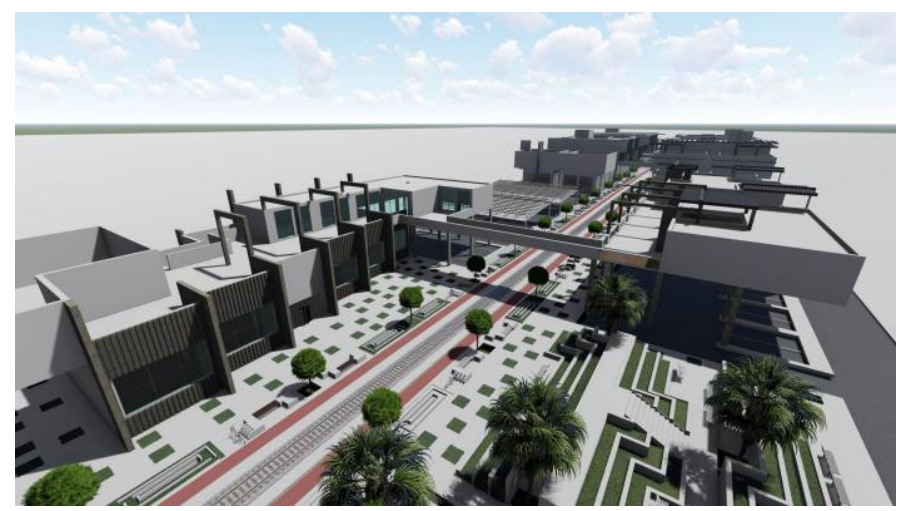

a. The Student Design.

Source: (The Author after One Architectural Student at MEU, 2020).
After the completion of project, at the end of second semester $2019 / 2020$, students present their project to external and internal design juries, who judge it according to:

- Concept quality.

- $\quad$ Reused of existing buildings.

- Spatial organization.

- $\quad$ Construction system an design material.

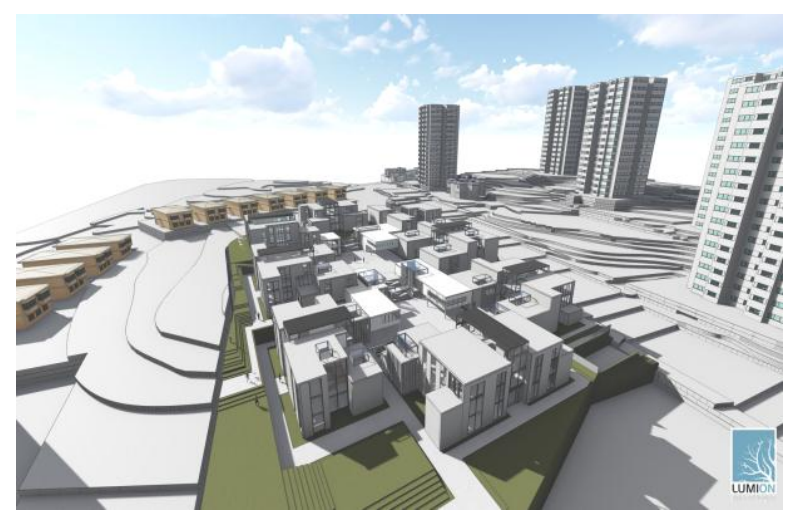

b. The Analogical Case; Housing in Ankara, Greece, by Yorum Birakin.

Source: (https://www.arch2o.com/ retrieved September 2020)

Figure 5. One of the Student Design of the Airport Urban Renewal Project. 


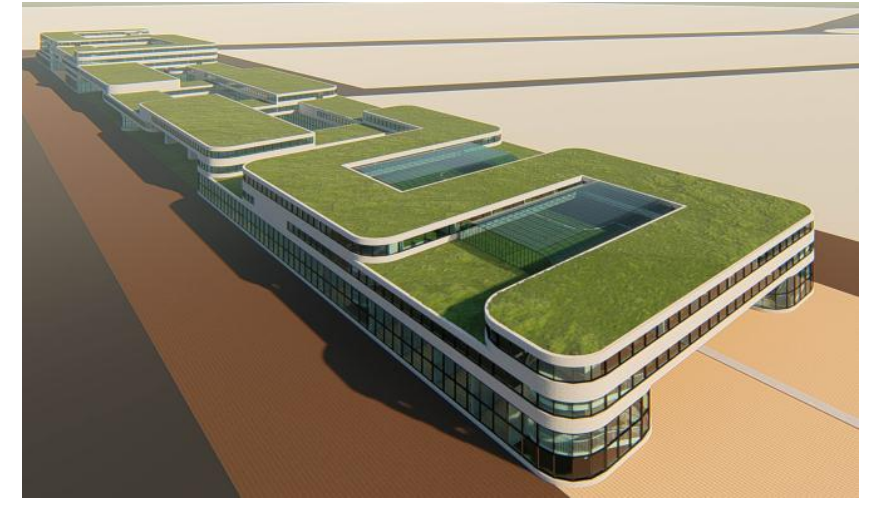

a. The Student Design.

Source: (The Author after One Architectural Student at MEU, 2020).

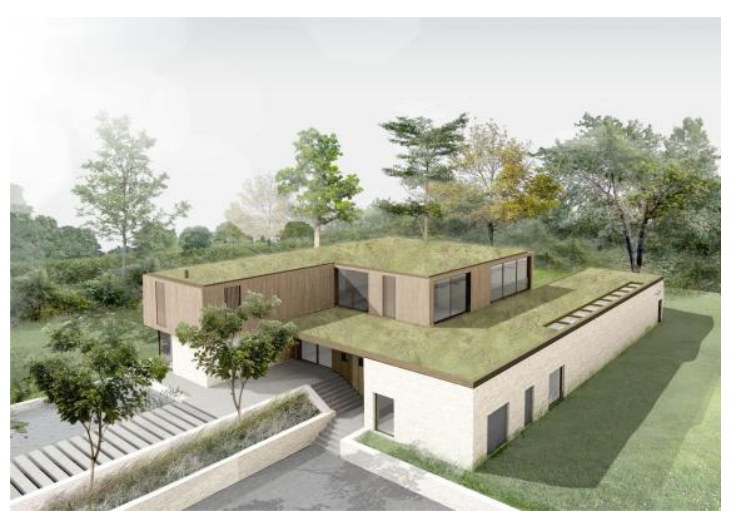

b. The Analogical Case; Col Legno House, by Phillips Tracey Architects Limited, USA.

Source: (https://www.arch2o.com/ retrieved September 2020)

Figure 6. One of the Student Design of the AlGiza Railway Station Project.

The results are examined by a slandered regression analysis, which is a method to understand the impact of the independent variables of the design on the dependent ones. The dependent variables, which had been used, are: concept, function, form, structure, material, and renewal aspects.

Students projects support the idea that using CBD method depend on the option that students has selected, in which the Airport Urban Renewal Project group were affected positively on their quality of the design. This is due to the content of the $\mathrm{CBD}$, which has more cases to choose from. Therefore, CBD method efficiency is determined by the quality, quantity, and variety of the information of the cases that have been chosen; the more variety of the cases the more options and details of design students.

These results overlap with what researchers named it as an analogical reasoning (Akin, 2002); (Heylighen, 2003), which argues that human uses analogies that is found to be guided by three constraints: the degree of similarity of the design cases, identify structural similarity of the design cases, and the analogy or metaphor goal.

\subsection{Results}

The paper is about Case-based Design (CBD). It is a teaching process using in the architectural education. It practices the method of case analysis in which students learn:

- Principles of the cases or events.

- Ways of applying these principles to a specific situation (case) to solve different kinds of design problems.

This is called the didactic (teaching) approach, which depends on a systematic representation of the principles of knowledge for a specific domain in which solving design problems abilities can be created (Akin, 2002). The students are given many precedents (cases) from which they can learn different interpretational techniques. This called the experiential (experimental) approach.
Students can learn through generate and experiment manner. So, students learn by applying beliefs to designs and concluding principles from them (Suwa and Tversky, 1997).

Four forms of instruction are important in the architectural educational programs: didactic (for lecture courses), rhetorical method, to understand sample texts and images from a relevant context domain, related with public speaking (for seminar classes), synthetic (for studio), and experiential (practical) (Heylighen and Verstijnen, 2003).

It was found that:

- Cases are used on the basis of a single aspect at a time.

- Cases were used for generation and evaluation purposes.

\section{CONCLUSION}

The paper focuses on the importance of using BIM in architectural design education. The study suggested an architectural design matrix for students to develop a project based on knowledge of BIM educational approach. The approach covers three major procedures that provide detailed guidelines for novices students to design, which are; Environmental (Contextual Aspects), Economic (Functional Relations), and Social (Spatial Relations). Furthermore, fivelevel BIM sequential phases were suggested for assisting students to organize their design with suitable design issues to choose from. To check the findings, the study applied the suggested approach on developing a BIM learning approach depending on CBD that examined on Middle East University students. The results of the experiment discovered that using a project design that based on prior cases could be a helpful teaching method for students as well as tutors. Moreover, with an actual design project and different learning settings, students are more motivated to learn BIM techniques depending on CBD. Nevertheless, this approach could drop the communication between tutors and students. Therefore, the tutor may need to give more work in tracing the knowledge development of students. While, the findings of the study 
showed that such a teaching approach could have a helpful effect on students' learning success, but there are still some limits of this study. Additional studies can adapt a statistical analysis of students' designs, or implement the proposed approach and compare it to other architectural teaching approaches.

\section{REFERENCES}

[1] Agirbas, A. 2020. Teaching Construction Sciences with the Integration of BIM to Undergraduate Architecture Students. Frontiers of Architectural Research, April 2020. https://doi.org/10.1016/j.foar.2020.03.007

[2] Akin, O. 2002. Case-Based Instruction Strategies in Architecture. Design Studies, 23(4): 407-431. https://doi.org/10.1016/S0142-694X(01)00046-1

[3] Berwald, S. 2008. From CAD to BIM: The Experience of Architectural Education with Building Information Modeling. Proceedings of Architectural Engineering Conference (AEI), Denver, Colorado, 2008: 211-230.

[4] Boton, C., Forgues, D., and Halin, G. 2018. A Framework for Building Information Modeling Implementation in Engineering Education. Canadian Journal of Civil Engineering, 45(10): 866-877. https://doi:10.1139/cjce-2018-0047

[5] Chen, Y., et al. 2019. Adoption of Building Information Modeling in Chinese Construction Industry. Engineering Construction Architecture Management, 26(9): 1878-1898. https://doi:10.1108/ECAM-11-20170246

[6] Domeshek, E. and Kolodner, J. 1993. Using the Points of Large Cases. Artificial Intelligent Engineering, 7(2): 87-96.

[7] Ericsson, A. and Simon, H. 1993. Protocol Analysis. Cambridge: MIT Press.

[8] Flemming, U. et al. 1997. Case-based Design in a Software Environment that Supports the Early Phases in Building Design. In: Maher ML, Pu P (eds) Issues and Applications of CBR in Design, Lawrence Erlbaum, London, 1997: 61-85.

[9] Heylighen, A. 2003. Stories from the Case Study Shop Floor. In: Malecha, M. (ed.), Case Study Production and Use, Proceedings of the AIA Case Study Workgroup, San Francisco, May 30-31: 17-21.

[10] Heylighen, A. and Verstijnen, I. 2003. Close Encounters of the Architectural Kind. Design Studies, 24(4): 313-326. https://doi.org/10.1016/S0142694X(02)00040-6

[11] Hua, K., Faltings, B., and Smith, I. 1996. CADRE: Case-based Geometric Design. Artificial Intelligent Engineering, 10: 171-183.

[12] Kalay, Y. 2004. Architecture's New Media: Principles, Theories, and Methods of Computer-Aided Design. Cambridge, Mass: MIT Press.
[13] Kocaturk, T. and Kiviniemi, A. 2013. Challenges of Integrating BIM in Architectural Education. Proceedings of the 31st Education and Research in Computer Aided Architectural Design in Europe Conference, (eCAADe), Faculty of Architecture, Delft University of Technology, Delft, The Netherlands, 2013: 115-129.

[14] Lee, S., Lee, J. and Ahn, Y. 2019. Sustainable BIMBased Construction Engineering Education Curriculum for Practice-Oriented Training. Sustainability, 11(21): 6120. https://doi.org/10.3390/su11216120

[15] March, L. 1976. The Architecture of Form. Cambridge: Cambridge University Press.

[16] Marcos, C. 2017. BIM Implications in the Design Process and Project-Based Learning: Comprehensive Integration of BIM in Architecture. WIT Transactions on the Built Environment, 169(1): 113-125. https://doi:10.2495/BIM170111

[17] Martin, W., Heylighen, A. and Cavallin, H. 2005. The Right Story at the Right Time: Towards a Tacit Knowledge Resource for (Student) Designers. AI \& Society, 19(1): 34-47. https://doi.org/10.1007/s00146004-0300-7

[18] Mitchell, W. 1990. The Logic of Architecture: Design Computation and Cognition. Cambridge: Massachusetts Institute of Technology.

[19] Motawa, M. and Almarshad, A. 2015. Case-Based Reasoning and BIM Systems for Asset Management. Built Environment Project and Asset Management, 5(3): 233-247. https://doi10.1108/BEPAM-02-20140006

[20] Oxman, R. and Oxman, R. 1994. Rememberance of Things in the Past: Design Precedents in Libraries. In: Tzonis A, White I (eds) Automation Based Creative Design. Research and Perspectives. Elsevier, Amsterdam, 1994: 55-68.

[21] Olatunji, O. 2019. Promoting Student Commitment to $\mathrm{BIM}$ in Construction Education. Engineering Construction Architecture Management, 26(3): 12401260. https://doi.10.1108/ECAM-04-2018-0173

[22] Rahman, R., Ayer, A., and London, J. 2019. Applying Problem-Based Learning in a Building Information Modeling Course. International Journal of Engineering Education, 35(3): 956-967.

[23] Reizgevicius, M., et al. 2018. Promoting Sustainability through Investment in Building Information Modeling (BIM) Technologies: A Design Company Perspective. Sustainability, 10(3): 600. https://doi.10.3390/ su10030600

[24] Richter, M., and Aamodt, A. 2005. Case-based Reasoning Foundations. The Knowledge Engineering Review, 20(3): 203-207. https://doi.10.1017/S 0269888906000695

[25] Rittel, H., and Webber, M. 1973. Dilemmas in a General Theory of Planning. Policy Sciences, 4(2): 155-169. 
International Journal of Engineering Research and Technology. ISSN 0974-3154, Volume 13, Number 10 (2020), pp. 2637-2646

(C) International Research Publication House. https://dx.doi.org/10.37624/IJERT/13.10.2020.2637-2646

[26] Reddy, K. 2012. BIM for Building Owners and Developers: Making a Business Case for Using BIM on Projects. United States of America: John Wiley \& Son, Inc.

[27] Rogers, J., et al. 2015. Adoption of Building Information Modelling Technology (BIM). Engineering Construction Architecture Management, 22(4): 424-445. https://doi:10.1108/ECAM-05-20140067

[28] Schank, R. 2000. Tell Me a Story: Narrative and Intelligence. Evanston: Northwestern University Press.

[29] Schmidt-Belz, B., Hovestadt, L. 1996. Scenario for an Integrated Design Support for Architects. Design Studies, 17(4): 489-509.

[30] Segers, N. 2004. Computational Representations of Words and Associations in Architectural Design. Eindhoven: Eindhoven Technische Universiteit.

[31] Smith, I., Stalker, R., and Lottaz, C. 1996. Creating Design Objects from Cases for Interactive Spatial Composition. In: Gero JS, Sudweeks F (eds) Artificial Intelligence in Design, Kluwer,Dordrecht, 1996:97116.

[32] Simon, H., 1992. The Sciences of the Artificial. Second Edition. Cambridge: Massachusetts Institute of Technology.

[33] Suwa, M. and Tversky, B. 1997. What Do Architects and Students Perceive in their Design Sketches? A Protocol Analysis. Design Studies, 18(4), 385-403. https://doi:10.1016/S0142-694X(97)00008-2

[34] Techel, F. and Nassar, K. 2007. Teaching Building Information Modeling (BIM) from a Sustainability Design Perspective. Proceedings of the Fifth International Conference of the Arab Society for Computer Aided Architectural Design ASCAAD, Embodying Virtual Architecture, Alexandria, Egypt, 2007: 635-650.

[35] Tsai, M., Chen, K., and Chang, Y. 2019. Development of a Project-Based Online Course for BIM Learning. $\begin{array}{llll}\text { Sustainability, } & 11 & \text { (21), } & 5772 .\end{array}$ https://doi:10.3390/su11205772

[36] Vinsova, I., et al. 2015. Integrating BIM in Education: Lessons Learned. Proceedings of the 33rd Education and Research in Computer Aided Architectural Design in Europe Conference, (eCAADe), Vienna University of Technology, Vienna, Austria, 2015: 127-131.

[37] Wu, W. and Issa, R. 2014. BIM Education and Recruiting: Survey-Based Comparative Analysis of Issues, Perceptions, and Collaboration Opportunities. Journal of Professional Issues in Engineering Education and Practice, 140(2): 1943-1962. https://doi.org/10.1061/(ASCE)EI.1943-5541.0000186 